\title{
Competência clínica em enfermagem para a ressuscitação cardiopulmonar de alta qualidade: revisão integrativa da literatura
}

\author{
Clinical competence in nursing for high quality cardiopulmonary resuscitation: an integrative \\ literature review
}

\section{Competencia clínica en enfermería para la reanimación cardiopulmonar de alta calidad: revisión integradora de la literatura}

\section{RESUMO}

Objetivo: Identificar as evidências científicas disponíveis na literatura sobre as habilidades necessárias ao desenvolvimento de competência clínica em Suporte Básico de Vida para enfermagem. Método: Revisão integrativa, nas fontes National Library of Medicine (NLM), National Institutes of Health (NIH), Cumulative Index to Nursing and Allied Health Literature (CINAHL), Literatura Latino-Americana e do Caribe em Ciências da Saúde (LILACS), Web of Science e SCOPUS. Utilizou-se o Rayyan para a seleção e a Análise Temática. Resultados: Identificaram-se 753 estudos e cinco compuseram a amostra. Elaboraram-se duas categorias; habilidades cognitivas e psicomotoras para o Suporte Básico de Vida e as habilidades afetivas. Conclusão: As habilidades cognitivas e psicomotoras abordam, desde a capacidade de definir a parada cardiorrespiratória e compreender o Suporte Básico de Vida, até as ações necessárias ao atendimento. A literatura explora essa categoria, em detrimento às habilidades afetivas, uma lacuna científica, já que são essenciais para a qualidade da ressuscitação cardiopulmonar.

Descritores: Enfermagem; Competência Clínica; Reanimação Cardiopulmonar; Aprendizagem; Ensino.

\section{ABSTRACT}

Purpose: To identify the scientific evidence available in the literature on the skills needed to develop clinical competence in Basic Life Support for nursing. Method: Integrative review, in the sources National Library of Medicine (NLM), National Institutes of Health $(\mathrm{NIH})$, Cumulative Index to Nursing and Allied Health Literature (CINAHL), Latin American and Caribbean Literature in Health Sciences (LILACS), Web of Science and SCOPUS. Rayyan was used for selection and Thematic Analysis. Results: 753 studies were identified and five comprised the sample. Two categories were elaborated; cognitive and psychomotor skills for Basic Life Support and affective skills. Conclusion: Cognitive and psychomotor skills range from the ability to define the cardiorespiratory arrest and understand the Basic Life Support, to the actions necessary for care. The literature explores this category, to the detriment of affective skills, a scientific gap, as they are essential for the quality of cardiopulmonary resuscitation.

Descriptors: Nursing; Clinical Competence; Cardiopulmonary resuscitation; Learning; Teaching.

\section{RESUMEN}

Objetivo: Identificar la evidencia científica disponible en la literatura sobre las habilidades necesarias para desarrollar la competencia clínica en Soporte Vital Básico para enfermería. Método: Revisión integrativa, en fuentes Biblioteca Nacional de Medicina (NLM), Institutos Nacionales de Salud (NIH), Índice Acumulado de Literatura de Enfermería y Afines en Salud (CINAHL), Literatura Latinoamericana y Caribe en Ciencias de Salud (LILACS), Web of Ciencia y SCOPUS. Rayyan se utilizó para selección y análisis temático. Resultados: Se identificaron 753 estudios y cinco conformaron la muestra. Se elaboraron dos categorías; Habilidades cognitivas y psicomotoras para soporte vital básico y habilidades afectivas. Conclusión: Las habilidades cognitivas y psicomotoras van desde la capacidad para definir el paro cardiorrespiratorio y comprender el Soporte Vital Básico, hasta las acciones necesarias para el cuidado. La literatura explora esta categoría, en detrimento de las habilidades afectivas, un vacío científico, ya que son fundamentales para la calidad de reanimación cardiopulmonar. Descriptores: Enfermería; Competencia Clínica; Reanimación Cardiopulmonar; Aprendizaje; Enseñanza.
Juliana da Silva Garcia Nascimento ${ }^{1}$ 0000-0003-1118-2738

Kleiton Gonçalves do Nascimento ${ }^{2}$ $\underline{0000-0002-2717-6837}$

Daniela da Silva Garcia Regino ${ }^{3}$ $\underline{0000-0003-0045-7783}$

Mateus Goulart Alves ${ }^{4}$ 0000-0003-0680-6817

Jordana Luiza Gouvêa de Oliveira ${ }^{1}$ 0000-0001-5905-8993

Maria Celia Barcellos Dalri ${ }^{1}$ 0000-0002-8173-8642

${ }^{1}$ Escola de Enfermagem de Ribeirão Preto, SP, Brasil.

2 Universidade Federal do Triângulo Mineiro, MG, Brasil.

3 Universidade Brasil, SP, Brasil.

${ }^{4}$ Universidade de Franca, SP, Brasil.

Autor correspondente: Juliana da Silva Garcia Nascimento E-mail: mestradounesp28@yahoo.com.br

Como citar este artigo:
Nascimento JSG, Nascimento KG, Regino
DSG, et al. Competência clínica em
enfermagem para a ressuscitação
cardiopulmonar de alta qualidade: revisão
integrativa da literatura. Revista de
Enfermagem do Centro-Oeste Mineiro.
2021;11:e3949. [Access__]; Available
in:_ DOI:
$\underline{\text { http://dx.doi.org/10.19175/recom.v11i0.39 }}$
$\underline{49}$

Nascimento JSG, Nascimento KG, Regino DSG, et al. Competência clínica em enfermagem para a ressuscitação cardiopulmonar de alta qualidade: revisão integrativa da literatura. Revista de Enfermagem do Centro-Oeste Mineiro. 2021;11:e3949. [Access___]; Available http://dx.doi.org/10.19175/recom.v11i0.39 $\underline{49}$ 
2|Nascimento JSG, NascimentoKG, Regino DSG, et al.

\section{INTRODUÇÃO}

A parada cardiorrespiratória (PCR) definese pela cessação da atividade mecânica do coração, confirmada pela ausência de sinais de circulação, restabelecida por meio da ressuscitação cardiopulmonar (RCP) de alta qualidade, composta, a priori, por um conjunto de medidas e procedimentos técnicos para o suporte à vida de uma vítima, denominado Suporte Básico de Vida (SBV) ${ }^{(1)}$.

É indiscutível o impacto positivo da identificação precoce de uma PCR, acionamento do serviço médico de emergência e de uma RCP bem-sucedida, com SBV e desfibrilação, já que o comprometimento neuronal da vítima ocorre após dois minutos de $\mathrm{PCR}^{(2)}$. Diante da importância do SBV, a American Heart Association (AHA) aborda a necessidade de investir no desenvolvimento de competência clínica dos profissionais de saúde para a RCP, na intencionalidade de torná-los aptos e seguros quanto à tomada de decisão, aprimorar o seu conhecimento teórico-prático e o equilíbrio emocional ${ }^{(3-4)}$.

O profissional enfermeiro possui um papel fundamental neste contexto, principalmente, por ocupar uma posição de liderança perante a sua equipe e pela proximidade com o paciente, o que permite uma observação mais atenta, quanto aos sinais de deterioração fisiológica que precede a PCR, sua atuação precoce e organização do atendimento, condição que the exige competência clínica para aplicar o SBV de forma eficaz ${ }^{(3)}$. Neste estudo, considerou-se como competência clínica à enfermagem no SBV, um saber agir complexo, baseado na tríade: habilidades cognitivas (conhecimento), habilidades psicomotoras (prática) e habilidades afetivas (comportamento) ${ }^{(5)}$, que possibilitam 0 atendimento eficaz baseado em um julgamento clínico sólido ${ }^{(6)}$.

A problemática existente, quanto ao desenvolvimento de competência clínica na enfermagem, especificamente para o SBV, está, principalmente, em como estruturá-la, mensurála e avaliá-la, o que indica a necessidade de obter clareza sobre quais são as habilidades necessárias para um SBV de alta qualidade ${ }^{(7-11)}$. No entanto a escassa exploração científica sobre o tema, somada à sua fundamentalidade, para o processo de ensino e aprendizagem em enfermagem e a segurança dos pacientes ${ }^{(12)}$, instiga e justifica 0 aprofundamento científico neste âmbito. Este estudo apresentou como objetivo identificar as evidências científicas disponíveis na literatura sobre as habilidades necessárias ao desenvolvimento de competência clínica em SBV para enfermagem.

\section{MÉTODO}

Trata-se de uma revisão integrativa da literatura, realizada de março a agosto de 2020, em uma universidade pública do interior de São Paulo, Brasil, cujo desenvolvimento percorreu as seguintes etapas: identificação do tema e questão norteadora; busca e seleção dos estudos na literatura; categorização dos estudos; análise dos estudos selecionados e apresentação da revisão(13), adotando-se a recomendação PRISMA $^{(14)}$, configurada por um checklist de 27 itens e um fluxograma de quatro etapas, que subsidiaram o rigor e qualidade metodológica desta revisão.

Utilizou-se a estratégia PatientIntervention-Outcomes- PIO, uma variação da estratégia Patient-Intervention-ComparationOutcomes-PICO(15), para elaborar a questão de pesquisa. $O$ acrônimo $P$ (população) foi representado por estudantes de enfermagem e profissionais enfermeiros, o acrônimo । (intervenção) pela identificação das habilidades necessárias ao desenvolvimento de competência clínica para o SBV de vítimas adultas e o acrônimo O (desfecho) a realização de um SBV de alta qualidade.

Desta forma, obteve-se a seguinte pergunta norteadora de pesquisa: Quais as evidências científicas disponíveis na literatura sobre as habilidades necessárias ao desenvolvimento de competência clínica no SBV para a enfermagem?

Determinaram-se os seguintes critérios de inclusão: estudos primários, que respondessem à questão norteadora, sem delimitação de idioma, a partir de 2015, ano que contemplou atualizações substanciais, nas diretrizes da ressuscitação cardiopulmonar em adultos, como também estudos publicados em periódicos científicos e disponíveis eletronicamente. Revisões da literatura, estudos de caso, dissertações, teses, monografias, resumos publicados em anais de eventos, manuscritos que abordassem o processo de ensino e aprendizagem do SBV neonatal e pediátrico e para pessoas leigas foram excluídos.

Realizou-se a busca dos estudos, em junho de 2020, nas bases de dados: National Library of Medicine (NLM), National Institutes of Health 
$(\mathrm{NIH})$, Cumulative Index to Nursing and Allied Health Literature (CINAHL), Literatura LatinoAmericana e do Caribe em Ciências da Saúde (LILACS), Web of Science e SCOPUS.

Na PubMed ${ }^{\circ}$ e Scopus, determinaram-se descritores controlados, na língua inglesa, identificados no Medical Subjects Headings (MeSH): Nurses; "Students, Nursing";" Clinical Competence"; "Cardiopulmonary Resuscitation". Realizaram-se as estratégias: (Nurses OR Nurse OR "Personnel, Nursing" OR "Nursing Personnel" $O R$ "Registered Nurses" OR "Nurse, Registered" OR "Nurses, Registered" OR "Registered Nurse" AND "Students, Nursing" OR "Pupil Nurses" OR "Student, Nursing" OR "Nurses, Pupil" OR "Nurse, Pupil" OR "Pupil Nurse" $O R$ "Nursing Student" $O R$ "Nursing Students" AND "Clinical Competence" OR "Competency, Clinical" OR "Competence, Clinical" $O R$ "Clinical Competency" OR "Clinical Competencies" $O R$ "Competencies, Clinical" $O R$ "Clinical Skill" OR "Skill, Clinical" OR "Skills, Clinical" OR "Clinical Skills" AND "Cardiopulmonary Resuscitation" OR "Resuscitation, Cardiopulmonary" OR CPR OR "Cardio-Pulmonary Resuscitation" OR "Cardio Pulmonary Resuscitation" OR "Resuscitation, Cardio-Pulmonary" OR "Code Blue" OR "Mouth-toMouth Resuscitation" OR "Mouth to Mouth Resuscitation" OR "Mouth-to-Mouth Resuscitations" OR "Resuscitation, Mouth-toMouth" OR "Resuscitations, Mouth-to-Mouth" OR "Basic Cardiac Life Support" OR "Life Support, Basic (ardiac").

$\mathrm{Na}$ CINAHL, os descritores controlados foram identificados em Títulos, na língua inglesa: Nurse;" Students, Nursing";" Clinical Competence"; "Resuscitation, Cardiopulmonary". Procedeu-se à estratégia: (Nurse AND "Students, Nursing" AND "Clinical Competence" OR "Nursing Skills" AND "Resuscitation, Cardiopulmonary").

$\mathrm{Na}$ Web of Science, adotaram-se os seguintes descritores, na língua inglesa: Nurses; "Students, Nursing"; "Clinical Competence"; "Resuscitation, Cardiopulmonary" e a estratégia utilizada foi: (Nurses AND "Students, Nursing" AND "Clinical Competence" AND "Resuscitation, Cardiopulmonary").

$\mathrm{Na}$ LILACS, os descritores controlados estavam presentes no Descritores de Ciências da Saúde (Decs), em inglês: Nurses; "Students, Nursing"; "Clinical Competence"; "Resuscitation, Cardiopulmonary", com a estratégia: Nurses AND "Students, Nursing" AND "Clinical Competence"
AND "Resuscitation, Cardiopulmonary". Em português: "Enfermeiras e Enfermeiros"; "Estudantes de Enfermagem"; "Competência Clínica"; "Reanimação Cardiopulmonar", com a estratégia: "Enfermeiras e Enfermeiros" AND "Estudantes de Enfermagem" AND Competência Clínica AND Reanimação Cardiopulmonar" e, em espanhol,: "Enfermeras y Enfermeros"; "Estudiantes de Enfermería"; "Competencia clínica"; "Reanimación cardiopulmonar", com a estratégia: "Estudiantes de Enfermería" AND "Competencia clínica" AND "Reanimación cardiopulmonar". Utilizaram-se os operadores booleanos AND e OR, capazes de realizar as combinações pretendidas entre os descritores na busca, sendo AND uma combinação restritiva e OR uma combinação $\operatorname{aditiva}^{(15)}$.

Foram identificados 753 estudos, submetidos à primeira etapa de seleção por dois profissionais, de forma independente, pela leitura de títulos e resumos, por meio de um programa de revisão gratuito da web de versão única denominado Rayyan Qatar Computing Research Institute (Rayyan QCRI) ${ }^{(16)}$, encontrado no link https://rayyan.qcri.org, que exporta os estudos identificados, em uma base de dados determinada e permite sua seleção rápida e organizada, com o devido cegamento do pesquisador auxiliar, o que garante a precisão metodológica deste processo ${ }^{(16)}$.

Apresentaram divergência entre a avaliação dos pesquisadores onze estudos, encaminhados a um terceiro, responsável por decidir sua inclusão ou a exclusão e, em seguida, realizou-se a leitura na íntegra, para definir a amostra final. Cabe ressaltar que procedeu-se a uma pesquisa manual, para analisar as listas de referências dos estudos, que compuseram a amostra da presente pesquisa, na intenção de identificar manuscritos que pudessem ser incluídos na seleção, no entanto nenhum outro estudo foi considerado elegível. Desta forma, extraíram-se as informações, utilizando-se um instrumento validado $^{(17)}$, que priorizou os seguintes critérios: autores; ano, origem do estudo; objetivo; tipo de estudo; amostra; resultados, conclusões, além da classificação do nível de evidência ${ }^{(18)}$.

Os achados foram analisados, por meio dos pressupostos da Análise Temática ${ }^{(19)}$ cumprindose três etapas: a pré-análise, configurada pela leitura flutuante das evidências e organização das informações convergentes, denominadas como unidades de registro; em seguida, a exploração do 
4|Nascimento JSG, Nascimento KG, Regino DSG, et al.

material com o agrupamento minucioso das unidades de registro identificadas e tratamento dos dados, determinando-se as categorias.

Em consonância com os aspectos éticos e legais da Resolução no 466/2012(20), a pesquisa não foi submetida ao Comitê de Ética em
Pesquisa, por se tratar de uma revisão da literatura e não envolver seres humanos. Por fim, demonstrou-se a seleção dos estudos, seguindo as recomendações Preferred Reporting Items for Systematic Reviews and Meta-Analyses (PRISMA) $)^{(14)}$, conforme apresentado na Figura 1.

Figura 1 - Fluxograma de identificação, seleção e inclusão dos estudos, elaborado a partir da recomendação Preferred Reporting Items for Systematic Reviews and Meta-Analyses (PRISMA). Ribeirão Preto, São Paulo, 2020.

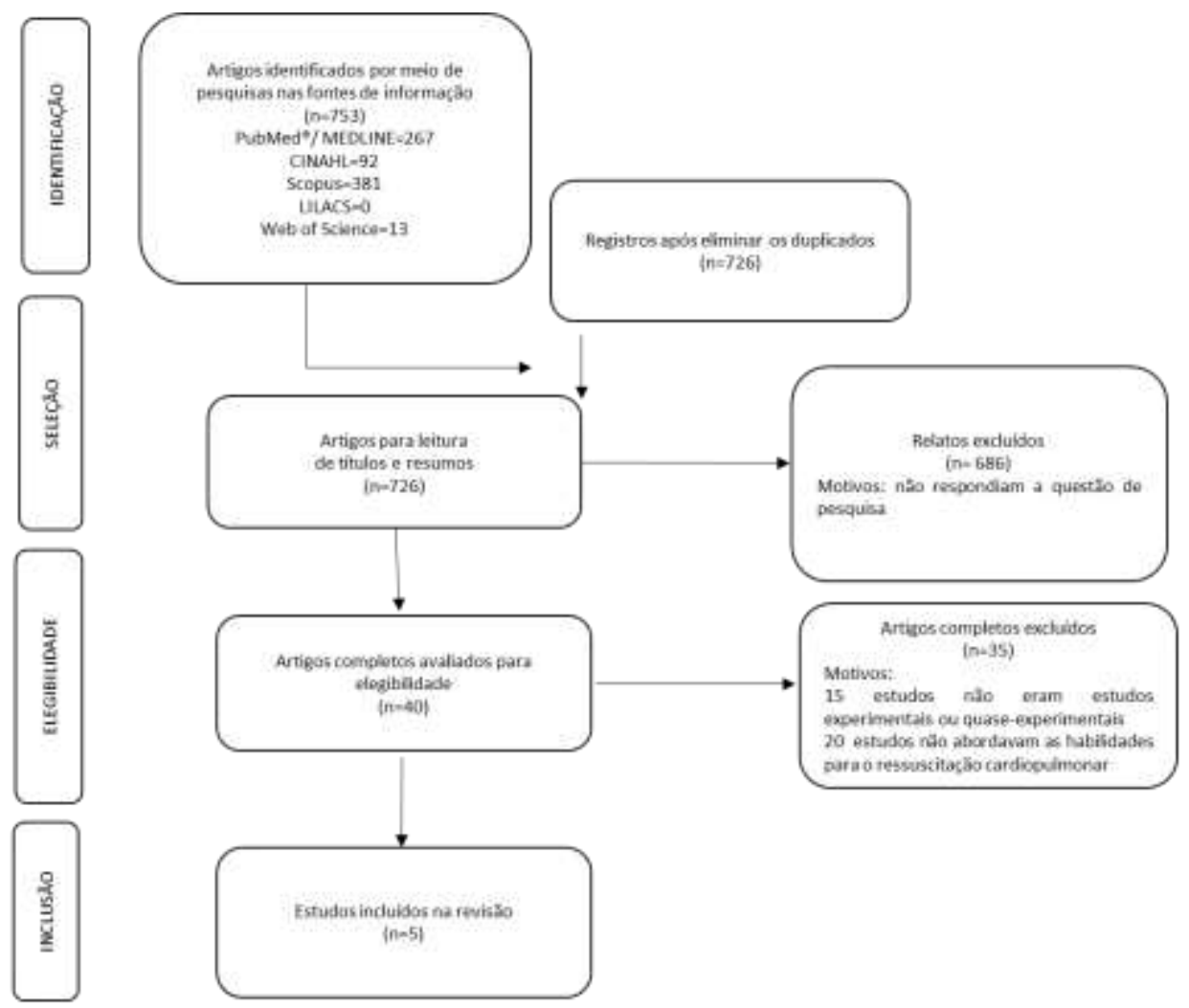

Fonte: Preferred Reporting Items for Systematic Reviews and Meta-Analyses (PRISMA)(14)

\section{RESULTADOS}

Compuseram a amostra do presente estudo cinco pesquisas primárias, caracterizadas na Figura 2, a seguir.

Figura 2 - Apresentação da caracterização dos estudos primários. Ribeirão Preto, São Paulo, 2020.

\begin{tabular}{|c|c|c|c|}
\hline $\begin{array}{c}\text { Autor, ano e } \\
\text { origem }\end{array}$ & $\begin{array}{l}\text { Objetivo do estudo e } \\
\text { habilidades avaliadas }\end{array}$ & $\begin{array}{l}\text { Tipo de estudo, amostra e } \\
\text { procedimento }\end{array}$ & $\begin{array}{l}\text { Principais resultados, conclusão e nível de } \\
\text { evidência }\end{array}$ \\
\hline $\begin{array}{l}\text { Roel S, Bjørk IT, } \\
2020 . \\
\text { Noruega. }\end{array}$ & $\begin{array}{l}\text { Comparar } \\
\text { desenvolvimento de } \\
\text { competência clínica } \\
\text { para RCP, em } \\
\text { estudantes r de } \\
\text { enfermagem, por } \\
\text { meio de mudança } \\
\text { curricular para o } \\
\text { ensino do SBV. } \\
\text { Habilidades: cognitiva } \\
\text { e psicomotoras. }\end{array}$ & $\begin{array}{l}\text { Estudo quase-experimental, } \\
\text { realizado com dois grupos de } \\
\text { estudantes de enfermagem. O } \\
\text { primeiro de } 60 \text { alunos realizou um } \\
\text { treinamento de SBV tradicional e o } \\
\text { segundo, de } 82 \text { alunos, participou } \\
\text { de um treinamento de RCP baseado } \\
\text { em simulação. A habilidade } \\
\text { cognitiva foi avaliada por um } \\
\text { questionário e as psicomotoras por } \\
\text { um dispositivo de feedback para } \\
\text { RCP. }\end{array}$ & $\begin{array}{l}\text { O Segundo grupo obteve uma pontuação na } \\
\text { habilidade cognitiva maior que o outro. Quanto às } \\
\text { habilidades psicomotoras, a média de } \\
\text { compressão, medida em milímitros foi bastante } \\
\text { semelhante em ambos os grupos ( } 55 \mathrm{~mm} \text {, no } \\
\text { primeiro e } 54,4 \mathrm{~mm} \text { no segundo). Os alunos do } \\
\text { segundo grupo obtiveram uma taxa média } \\
\text { significativamente maior de compressões por } \\
\text { minuto, porém posição incorreta das mãos. O } \\
\text { novo treinamento para RCP é capaz de } \\
\text { desenvolver competência clínica em estudantes. } \\
\text { Nível de evidência 3. }\end{array}$ \\
\hline
\end{tabular}


Figura 2 - Apresentação da caracterização dos estudos primários. Ribeirão Preto, São Paulo, 2020.

\begin{tabular}{|c|c|c|c|}
\hline $\begin{array}{l}\text { Autor, ano e } \\
\text { origem }\end{array}$ & $\begin{array}{l}\text { Objetivo do estudo e } \\
\text { habilidades avaliadas }\end{array}$ & $\begin{array}{c}\text { Tipo de estudo, amostra e } \\
\text { procedimento }\end{array}$ & $\begin{array}{l}\text { Principais resultados, conclusão e nível de } \\
\text { evidência }\end{array}$ \\
\hline $\begin{array}{lr}\text { Moon H, Hyun } \\
\text { HS, } & 2019 . \\
\text { Coreia } & \text { do } \\
\text { Sul(22). } & \end{array}$ & 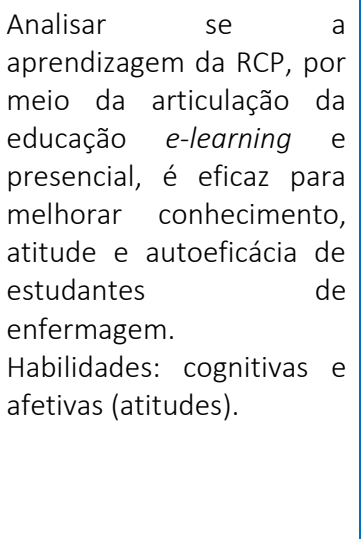 & \begin{tabular}{lrr} 
Estudo & \multicolumn{2}{r}{ experimental, } \\
randomizado, realizado com \\
120 estudantes \\
enfermagem. de \\
intervenção grupo \\
submetido à aprendizagem \\
mista, e o grupo controle \\
(n=60), a um treinamento \\
presencial para RCP. Adotou-se \\
um instrumento de 20 itens, \\
para avaliar o conhecimento, \\
um instrumento para avaliar \\
atitudes e uma escala para \\
autoeficácia.
\end{tabular} & $\begin{array}{l}\text { Os resultados indicaram que o grupo intervenção } \\
\text { teve escores de conhecimento significativamente } \\
\text { mais altos (intervenção: } 16,40 \pm 1,56 \text {, controle: } \\
6,46 \pm 2, p<0,001 \text { ) e atitude emocional } \\
\text { (intervenção: } 40,85 \pm 8,01 \text {, controle: } 36,05 \pm 6,87 \text {, } \\
p=0,002 \text { ) sobre a RCP que o grupo controle. } \\
\text { Concluiu-se que um programa misto, para o } \\
\text { aprendizado da RCP, foi considerado eficaz para } \\
\text { melhorar o conhecimento e as atitudes dos } \\
\text { estudantes de enfermagem em relação à RCP. } \\
\text { Nível de evidência } 2 \text {. }\end{array}$ \\
\hline $\begin{array}{l}\text { Munezero JBT, } \\
\text { Atuhaire C, } \\
\text { Groves S, } \\
\text { Cumber SN, } \\
2018 \\
\text { Uganda(23). }\end{array}$ & $\begin{array}{l}\text { Avaliar os conhecimentos } \\
\text { e } \\
\text { psicomotoras } \\
\text { enfermeiros dos } \\
\text { treinamento em RCP. } \\
\text { Habilidades: cognitivas e } \\
\text { psicomotoras. }\end{array}$ & $\begin{array}{l}\text { Estudo quase experimental, } \\
\text { realizado com } 32 \text { enfermeiros } \\
\text { em um hospital. Para avaliar a } \\
\text { habilidade cognitiva para RCP, } \\
\text { utilizou-se um questionário de } \\
17 \text { perguntas e, para verificar } \\
\text { as habilidades psicomotoras, } \\
\text { uma lista de verificação de } \\
\text { habilidades. }\end{array}$ & $\begin{array}{l}\text { A pontuação média do conhecimento no pré- } \\
\text { teste foi de } 53,8 \text { pontos e, após, } 82,5 \text { pontos. } \\
\text { Quanto às habilidades psicomotoras, antes da } \\
\text { intervenção, obtiveram-se } 46 \text { pontos e, após, } \\
81,5 \text {. Houve melhora significante }(p<0,001) \text { no } \\
\text { conhecimento sobre RCP }(p=0,02) \text { e nas } \\
\text { habilidades psicomotoras. O estudo revelou } \\
\text { melhora no conhecimento e nas habilidades. } \\
\text { Nível de evidência 3. }\end{array}$ \\
\hline $\begin{array}{l}\text { Tobase L, et al, } \\
2017 \\
\text { Brasil }^{(24)} \text {. }\end{array}$ & $\begin{array}{l}\text { Descrever os resultados de } \\
\text { aprendizagem de } \\
\text { estudantes em } \\
\text { enfermagem, após um } \\
\text { curso de suporte à vida. } \\
\text { Habilidades: cognitivas e } \\
\text { psicomotoras. }\end{array}$ & $\begin{array}{l}\text { Estudo do tipo quase- } \\
\text { experimental, que utilizou um } \\
\text { curso on-line de SBV para } 62 \\
\text { estudantes de enfermagem. } \\
\text { Testes foram adotados para } \\
\text { avaliar a habilidades cognitiva, } \\
\text { e uma lista de verificação para } \\
\text { as habilidades psicomotoras de } \\
\text { RCP. }\end{array}$ & $\begin{array}{l}\text { Revelou-se um aumento significativo na } \\
\text { habilidade cognitiva- pré-teste }[(6,4 \pm 1,61) \text {, pós- } \\
\text { teste }(9,3 \pm 0,82) \text {, p <0,001]. Os participantes } \\
\text { realizaram uma simulação de } R C P \text {, que teve uma } \\
\text { pontuação média } \pm \text { DP de } 9,1 \pm 0,95 \text {. O curso foi } \\
\text { um método eficaz para ensinar e aprender as } \\
\text { principais habilidades de SBV. Nível de evidência } \\
\text { 3. }\end{array}$ \\
\hline $\begin{array}{l}\text { MoslemiRad } \\
\text { M, et al, } 2019 . \\
\text { Irãn } \\
(25)\end{array}$ & $\begin{array}{l}\text { Determinar o efeito de } \\
\text { estratégias de baseadas } \\
\text { em evidências para a } \\
\text { competência clínica para } \\
\text { RCP. Hbilidades: cognitivas } \\
\text { e psicomotoras. }\end{array}$ & $\begin{array}{l}\text { Estudo quase-experimental, } \\
\text { realizado com } 44 \text { enfermeiros } \\
\text { em um Hospital, divididos em } \\
\text { dois grupos. O primeiro foi } \\
\text { submetido a uma estratégia } \\
\text { pedagógica, baseada em } \\
\text { evidências, e o segundo a } \\
\text { treinamento para RCP } \\
\text { tradicional. }\end{array}$ & $\begin{array}{l}\text { A competência clínica do grupo de aprendizado, } \\
\text { baseado em evidências, foi significativa para a } \\
\text { RCP, implementação de vias aéreas artificiais, } \\
\text { princípios de início e término da RCP }(p<0,05) \text {. O } \\
\text { ensino baseado em evidências para o SBV pode } \\
\text { ser eficaz no desenvolvimento de competência } \\
\text { clínica. Nível de evidência } 3 \text {. }\end{array}$ \\
\hline
\end{tabular}

Fonte: Dos autores (2020).

A amostra selecionada data de 2017 a 2020, caracterizada. na maioria, por estudos

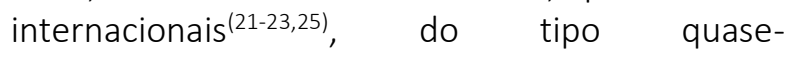
experimental(21,23-25), com nível de evidência 3. Elaboraram-se duas categorias: (1) habilidades cognitivas e psicomotoras pertinentes ao SBV e (2) habilidades afetivas pertinentes ao SBV.

A primeira categoria abordou as habilidades cognitivas e psicomotoras para o SBV, a partir do domínio dos seguintes critérios: definir $P C R^{(23)}$, causas da $P C R^{(23)}$, sinais e sintomas de uma vítima em $\mathrm{PCR}^{(23,25)}$, definição de $\mathrm{SBV}^{(23,25)}$, ações que compõem o atendimento no SBV ${ }^{(23,25)}$, Elos da Cadeia de Sobrevivência (25), identificação da responsividade da vítima ${ }^{(22,25)}$, disposição do socorrista ao lado ou próximo ao ombro da vítima ${ }^{(25)}$, identificação da respiração e movimentos ventilatório no toráx ${ }^{(22,24-25)}$, verificação do pulso carotídeo ${ }^{(24-25)}$, comunicação do serviço médico de emergência ${ }^{(24-25)}$, exposição do tórax da vítima ${ }^{(24)}$, realização da sobreposição das mãos ${ }^{(25)}$, disposição da região hipotenar da mão no centro do tórax da vítima ${ }^{(25)}$, disposição dos ombros a $90^{\circ}$ com o tórax da vítima ${ }^{(25)}$, 
número de compressões torácicas externas por minuto(23-25), frequência/velocidade das compressões torácicas externas por minuto(23-24), profundidade das compressões torácicas externas por minuto(23-24), posicionamento correto das mãos no tórax da vítima para compressão torácica externa ${ }^{(23-24)}$, descompressão e permissão do retorno do tórax da vítima durante as compressões torácicas externas(24-25), não flexão dos braços durante compressões torácicas ${ }^{(25)}$, realização da movimentação do tronco para aplicação da força nas compressões ${ }^{(25)}$, realização das compressões sem interrompê-la ${ }^{(25)}$, tempo de troca para que outro socorrista continue as compressões ${ }^{(25)}$, momento de interromper as compressões ${ }^{(25)}$, manuseio do desfibrilador externo automático ${ }^{(21,24)}$, ritmos cardíacos passíveis de choque ${ }^{(25)}$.

A categoria referente às habilidades afetivas pertinentes ao SBV destacou o domínio de três atitudes: (1) atitude emocional: referindose aos sentimentos de alguém sobre realizar o SBV para um paciente com parada cardíaca (ansiedade, satisfação) $)^{(22) ;}$ (2) atitude comportamental, que incluiu tentar fazer o melhor e o mais adequado para realizar a RCP, quando testemunhar um paciente em PCR (autoeficácia, confiança)(22); e (3) atitude cognitiva, saber que a execução da RCP imediata é importante para o resultado favorável de um paciente em $\mathrm{PCR}^{(22)}$.

As evidências identificadas permitiram, também, sintetizar cinco estratégias de ensino e aprendizagem, para desenvolver as habilidades cognitivas, psicomotoras e afetivas, para o SBV, a saber: (1) Programa de Educação em RCP: caracterizado por um processo de ensino e aprendizagem do SBV, durante três anos do curso de graduação em enfermagem. No primeiro ano, desenvolveram-se cinco palestras, que incluíram primeiros socorros básicos e obstrução das vias aéreas por corpo estranho, associada ao treinamento no centro de simulação com um instrutor. No segundo ano, aulas ministradas por instrutor com cenários de simulação sobre RCP e, no terceiro ano, simulação em um ambiente hospitalar de um acidente com posterior $P C R^{(21)}$.

(2) Programa educacional de aprendizado combinado para RCP, composto por quatro sessões: na primeira sessão, aula expositiva e palestras; na segunda sessão, adoção de videoaula sobre RCP, abordando definição de $\mathrm{RCP}$; processo de RCP, princípios básicos de RCP com compressão torácica e uso de desfibrilador. $\mathrm{Na}$ terceira sessão, um vídeo intitulado curso básico ao programa de educação em RCP padrão, com informações sobre PCR, casos de RCP com sucesso, processo de compressão torácica, casos de RCP em que ninguém estava disponível para ajudar, uso do desfibrilador automático, fornecimento de ventilações de resgate e, na quarta sessão, palestra e leitura/estudo de apostila com conhecimentos para RCP(22).

(3) Treinamento de RCP de quatro horas, com aplicação de pré e pós-teste: primeiramente ocorreu a análise das habilidades cognitivas sobre RCP e logo após, o treinamento de SBV de três horas, com manequim que simulava as características da fisiologia e anatomia de um adulto médio. Utilizaram-se dois instrumentos, o primeiro, consistia em 17 questões de múltipla escolha sobre PCR e RCP, abordando definição, causas, sinais e sintomas, complicações e ações para prevenir morte súbita. O segundo instrumento envolveu um teste de habilidades psicomotoras de 15 pontos, ajustado para avaliar as habilidades em RCP ${ }^{(23)}$.

(4) Curso de SBV autoinstrucional on-line de 20 horas, com um modelo de design instrucional denominado ADDIE (Análise, Design, Desenvolvimento, Implementação, Avaliação) e implementado por meio da plataforma Moodle: todos os alunos recebem login e senha para acesso ao ambiente virtual e foram supervisionados por oito enfermeiros, especialistas em educação a distância e emergência. Aplica-se, após, a simulação clínica para avaliar as habilidades psicomotoras dos alunos. Aplicaram-se as etapas de SBV exigidas em pares, por 2 minutos, usando um desfibrilador externo automático e um simulador de manequim com dispositivos de feedback de RCP, troca de papéis para verificação de habilidades em todos os procedimentos necessários ${ }^{(24)}$.

(5) Workshop baseado em evidências: incluiu duas oficinas de pesquisa de quatro sessões consecutivas (totalizando 8 horas), seguido por duas oficinas com base em evidências de atendimento de RCP (totalizando 8 horas). O conteúdo abrangeu uma introdução da enfermagem, baseada em evidências, abordando como definir uma questão clínica, como usar fontes de informação e criticar os artigos. Após, implementaram-se as oficinas sobre RCP, com enfoque no cuidado baseado em evidências e suas etapas para RCP correta. Durante dois 
meses, o aprendizado foi acompanhando e, logo após, avaliou-se a competência clínica, por meio de uma lista de verificação clínica ${ }^{(25)}$.

\section{DISCUSSÃO}

As evidências científicas sobre as habilidades cognitivas, psicomotoras e afetivas para o SBV foram apresentadas por estudos atuais e metodologicamente bem delineados, no entanto compõem uma escassa amostra que evidencia a necessidade de aprofundamento científico neste âmbito(24-25) .

Este estudo confere ineditismo à ciência da enfermagem e ressuscitação cardiopulmonar por apresentar um arcabouço de conhecimento, baseado em evidências científicas confiáveis, que sintetiza e organiza quais são as habilidades cognitivas, psicomotoras e afetivas necessárias, a fim de desenvolver a competência clínica para o SBV, mas, sobretudo, por identificar que as habilidades cognitivas (conhecimento) e psicomotoras (habilidades práticas) são mais valorizadas pelas pesquisas científicas, em detrimento às habilidades afetivas (comportamento e atitudes); e delimitar com precisão, os três aspectos da habilidade afetiva, necessários para aperfeiçoar o comportamento do enfermeiro quanto à PCR. Ainda, por explorar cinco possibilidades pedagógicas para o processo de ensino e aprendizagem do SBV, apontou alternativas instrucionais que propiciam o desenvolvimento das habilidades citadas.

É importante compreender que difundir este conhecimento é fundamental, para que cresça o número de estudantes e profissionais capazes de realizar um SBV de alta qualidade e, independente da estratégia educativa adotada, para que seja considerada apropriada, é necessário que tenha como base os protocolos atualizados do SBV, estabelecidos pelas diretrizes da American Heart Association ${ }^{(4,21)}$.

Diante dos resultados, notou-se que a categoria referente às habilidades cognitivas e psicomotoras, para o SBV ${ }^{(22-24)}$, sobrepõem $\mathrm{O}$ aprofundamento científico das habilidades afetivas (atitudes/comportamento) ${ }^{(23)}$ que se pode justificar pela dificuldade existente para avaliar, de maneira ampla, o desenvolvimento da competência clínica para o SBV, pela escassez de instrumentos validados, capazes de abranger a tríade das habilidades cognitivas, psicomotoras e afetivas, visto que a maioria dos constructos concentram-se, apenas, na avaliação das habilidades cognitivas e psicomotoras ${ }^{(5)}$.

Nesta perspectiva, uma pesquisa experimental, realizada com estudantes de um curso de graduação em enfermagem na Coreia do Sul, comparou estratégias de ensino para o SBV e sua eficácia no desenvolvimento das três habilidades: cognitiva, psicomotora e afetivas e identificou as principais atitudes dos enfermeiros, durante o SBV, caracterizando-as em atitude emocional, que aborda os sentimentos gerados pelo profissional ou estudante, durante o SBV, como ansiedade e satisfação; a atitude comportamental, que incluiu iniciativa, liderança, motivação e autoeficácia; e a atitude cognitiva, a consciência de suas responsabilidades quanto ao atendimento ${ }^{(23)}$.

$\mathrm{Na}$ atualidade, recomenda-se adotar a simulação clínica, como estratégia pedagógica, para possibilitar o desenvolvimento de competência clínica para o SBV, visto a sua eficiência para intensificar o processo de ensino e aprendizagem em urgência e emergência e por oferecer condições apropriadas, para viabilizar a avaliação não somente das habilidades cognitivas e psicomotoras, como também das afetivas, neste contexto $^{(1-4)}$.

Por fim, considera-se que o desenvolvimento de competência clínica, para uma determinada área na enfermagem, depende da articulação de diversos critérios, relativos às habilidades cognitivas, psicomotoras e afetivas e que, para a completude deste perfil, é essencial elaborar estudos que se proponham explorar e avaliar essas habilidades de forma ampla e consistente ${ }^{(5-6)}$.

A principal limitação deste estudo foi a escassa amostra de artigos científicos que abordam o desenvolvimento e avaliação das habilidades cognitivas, psicomotoras e afetivas para o SBV, fator que dificulta a comparação e discussão deste cenário, mas não interfere na qualidade da exposição dos achados e sua compreensão.

Com base nos resultados desta revisão, é possível agregar evidências capazes de fundamentar o desenvolvimento de competência clínica para o SBV em enfermagem, esclarecendo a tríade de habilidades que suporta essa condição e apontar, como implicação futura, a elaboração de manuscritos científicos bem delineados, que se comprometam avaliar as três habilidades e valorizar as atitudes no que diz respeito ao SBV. 


\section{CONCLUSÃO}

Identificaram-se cinco estudos que abordaram as habilidades necessárias para o SBV, a partir dos quais obtiveram-se duas categorias, as habilidades cognitivas e psicomotoras para 0 SBV, caracterizadas pelas ações referentes ao atendimento de uma PCR, por meio do SBV, e as habilidades afetivas, que abrangem a atitude emocional, comportamental e cognitiva para o SBV.

Sintetizaram-se as principais estratégias educacionais, para desenvolver habilidades cognitivas, psicomotoras e afetivas para o SBV; o Programa de Educação em RCP, Programa educacional de aprendizado combinado para RCP, Treinamento de RCP de quatro horas, Curso de SBV autoinstrucional on-line e Workshop baseado em evidências.

Este estudo contribui com a pesquisa, ensino e assistência em enfermagem, por evidenciar a tríade de habilidades necessárias, para desenvolver competência clínica para o SBV, apontar as três vertentes que compõem as habilidades afetivas, as quais se configuram como uma lacuna científica, passível de ser explorada, principalmente por estudos metodológicos que proponham desenvolver e validar instrumentos capazes de avaliar atitudes e comportamento, durante o SBV, no âmbito da enfermagem, e estudos clínicos experimentais, que analisem a eficácia de estratégias pedagógicas para desenvolver competência clínica no SBV e, ainda, por descrever possibilidades pedagógicas que sustentam o processo de ensino e aprendizagem deste tema.

\section{REFERÊNCIAS}

1 - Awadalla NJ, Al Humayed RS, Mahfouz AA. Experience of basic life support among King Khalid University Health Profession Students, Southwestern Saudi Arabia. Int J Environ Res Public Health 2020;17(13):4822. DOI: 10.3390/ijerph17134822

2 - El Sayed M, Al Assad R, Aad YA, Gharios N, Refaat MM, Tamim H. Measuring the impact of emergency medical services (EMS) on out-ofhospital cardiac arrest survival in a developing country: A key metric for EMS systems' performance. Medicine 2017;96(29):e7570. DOI: 10.1097/MD.0000000000007570
3 - Kose S, Akin S, Mendi O, Goktas S. The effectiveness of basic life support training on nursing students' knowledge and basic life support practices: A non-randomized quasiexperimental design. Afr Health Sci. 2020;20(2):966-76. DOI: 10.4314/ahs.v20i2.53

4 - Neumar RW, Shuster M, Callaway CW, Gent LM, Atkins DL, Bhanji F, et al. Part 1: Executive summary: 2015 American Heart Association Guidelines update for cardiopulmonary resuscitation and emer gency cardiovascular care. Circulation 2015;132(18):315-67. DOI: $\underline{10.1161 / C I R .0000000000000252}$

5 - Le Boterf G. Developing the competence of professionals. 3a ed. Porto Alegre: Artmed; 2003.

6 - Pijl-Zieber EM, Barton S, Konkin J, Awosoga O, Caine V. Competence and competency-based nursing education: Finding our way through the issues. Nurse Educ Today 2014;34(5):676-8. DOI: 10.1016/i.nedt.2013.09.007

7 - Alves MG, Carvalho MTM, Nascimento JSG, Oliveira JLG, Cyrrillo RMZ, Braga FTMM, et al. Construction and validation of objective structured clinical examination (osce) on cardiopulmonary resuscitation. Rev Min Enferm. 2019;23:e-1257. DOI: $\underline{2762.20190105}$

8-Son YL, Park PN, Ko SH. The effects of preclinical Objective Structured Clininal Examination (OSCE) on knowledge, nursing students confidence in core fundamental nursing skills and self-efficacy. J Korean Clin Health Sci. 2017;5(2):850-63.

DOI: 10.5977/jkasne.2015.21.1.75

9 - Hadi MA, Ali M, Haseeb A, Mohamed MMA, Elrggal ME, Cheema E. Impact of test anxiety on pharmacy students' performance in Objective Structured Clinical Examination: A cross-sectional survey. Int J Pharm Pract. 2017;26(2):191-4. DOI: 10.1111/ijpp.12389

10 - Johnston AMB, Weeks B, Shuker MA, Coyne E, Mitchell M, Massey D. Nursing students' perceptions of the objective structured clinical examination: An integrative review. Clin Simul Nurs. 2017;13(3):127-42. DOI: 10.1016/j.ecns.2016.11.002 
11 - Zieber M, Sedgewick M. Competence, confidence and knowledge retention in undergraduate nursing students: A mixed method study. Nurse Educ Today 2018;62:16-21. DOI: 10.1016/j.nedt.2017.12.008

12 - Costa IKF, Tibúrcio MP, Costa IKF, Dantas RAN, Galvão RN, Torres GV. Development of a virtual simulation game on basic life support. Rev EsC Enferm USP 2018;52:e03382. DOI: $\underline{10.1590 / S 1980-220 \times 2017047903382}$

13- Whittemore $R$, Knafl $K$. The integrative review: Updated methodology. J Adv Nurs. 2005;52(5):546-53. DOI: $10.1111 / \mathrm{j} .1365-$ $\underline{2648.2005 .03621 . x}$

14 - Moher D, Liberati A, Tetzlaff J, Altman DG. Preferred reporting items for systematic reviews and metaanalyses: The PRISMA statement. PLOS Med. 2009;6(7):e1000097. DOI: $\underline{10.1371 / \text { journal.pmed.1000097 }}$

15 - Santos CM, Pimenta CA, Nobre MR. The pico strategy for the research question construction and evidence search. Rev Latino-Am Enfermagem 2007;15(3):508-11. DOI: 10.1590/S0104$\underline{11692007000300023}$

16- Ouzzani M, Hammady H, Fedorowicz Z, Elmagarmid A. Rayyan-a web and mobile app for systematic reviews. Syst Rev. 2016;5(1):210. DOI: $\underline{10.1186 / \mathrm{s} 13643-016-0384-4}$

17 - Ursi ES, Galvão CM. Perioperative prevention of skin injury: An integrative literature review. Rev Latino-Am Enfermagem 2006;14(1):124-31. DOI: $\underline{10.1590 / 50104-11692006000100017}$

18 - Melnyk BM, Fineout-Overholt E. Evidencebased practice in nursing \& healthcare: $A$ guide to best practice. 2a ed. Philadelphia: Wolters Kluwer Health/Pippincott Williams \& Wilkins; 2011.

19 - Minayo MC. Sampling and saturation in qualitative research: Consensuses and controversies. Rev Pesquisa Qualitativa 2017 [citado em 17 jun 2020]; 5(7):1-12. Acesso em: https://editora.sepq.org.br/index.php/rpq/article/ view/82/59

20 - Brasil. Conselho Nacional de Saúde. Resolução no 466, de 12 de dezembro de 2012. Dispõe sobre diretrizes e normas regulamentadoras de pesquisas envolvendo seres humanos. Diário Oficial [da] República Federativa do Brasil 2013 [citado em 17 jun 2020]. Acesso em:

https://bvsms.saude.gov.br/bvs/saudelegis/cns/2 013/res0466 $12 \quad 12 \quad 2012 . h t m l$

21 - Roel S, Bjørk IT. Comparing Nursing Student Competence in CPR before and after a Pedagogical Intervention. Nurs Res Pract. 2020;(7):1-6. DOI: 10.1155/2020/7459084

22 - Moon H, Hyun HS. Nursing students' knowledge, attitude, selfefficacy in blended learning of cardiopulmonary resuscitation: A randomized controlled trial. BMC Med Educ 2019;19:414. DOI: 10.1186/s12909-019-1848-8

23 - Munezero JBT, Atuhaire C, Groves S, Cumber $\mathrm{SN}$. Assessment of nurses knowledge and skills following cardiopulmonary resuscitation training at Mbarara Regional Referral Hospital, Uganda. Pan Afr Med J. 2018;30:108. DOI: $\underline{10.11604 / \text { pamj.2018.30.108.15398 }}$

24 - Tobase L, Peres HHC, Gianotto-Oliveira R, Smith N, Polastri TF, Timerman S. The effects of an online basic life support course on undergraduate nursing students' learning. J Med Educ. 2017;8:309-13. DOI: 10.5116/ijme.5985.cbce

25 - MoslemiRad M, Zaker MA, Elahi N, Hossein $M$. Investigating the effect of two evidence-based and routinebased learning techniques on the clinical competency of cardio-pulmonary resuscitation on emergency ward nurses in Imam Khomeini Dehdasht Hospital in 2017 Haghighizadeh. J Res Med Dent Sci. 2019 [cited 2020 Jul 6];7(1):52-60. Available in: https://www.jrmds.in/articles/investigating-theeffect-of-two-evidencebased-and-routinebasedlearning-techniques-on-the-clinical-competencyof-cardiopulmonary-r-5656.html

\section{Editores Responsáveis:}

Juliana Dias Reis Pessalácia Helisamara Mota Guedes Note: Este estudo é um recorte da tese de doutorado
intitulada "Efetividade do co-debriefing na simulação clínica
do suporte básico de vida: estudo piloto" do Programa de
Pós-graduação em Enfermagem Fundamental da Escola de
Enfermagem de Ribeirão Preto. Financiamento da
Coordenação de Aperfeiçoamento de Pessoal de Nível
Superior (CAPES).
Recebido em: $14 / 08 / 2020$
Aprovado em: $29 / 03 / 2021$ 